\title{
Revisiting Peer Classroom Observations as A Teacher Professional Development Protocol: A Critical Theoretical Review of Global Practices
}

\section{Quang Nhat Nguyen}

\section{Article history}

Received: 20 May 2021

Accepted: 18 June 2021

Published: 30 June 2021

\section{Keywords}

Peer observation, teacher professional development, models of observation, evaluative, collaborative, peer review of teaching

\author{
HQT Education Ltd., Ho Chi Minh City, Vietnam \\ Email: nhatquang.ed@gmail.com
}

\section{INTRODUCTION}

Professional development is a multilateral aspect of any professional life (Bush, 2007). In teaching, teachers' professional development is their professional, personal, experiential, intellectual, and emotional growth in all aspects of their career pursuit. Teacher professional development activities can increase teacher knowledge, collegiality, and personal improvement (Borko, 2004; Guskey, 2002). Besides their gains, teachers play an essential role in developing their institutional reputation and ranking by pursuing their professional development. Although teacher professional development relates to many areas, this review focuses on teacher's development as a process that facilitates teachers in enhancing their teaching performance in the classroom. Nevertheless, the author feels that teacher professional development should relate to other aspects of a teacher's professional life, such as work politics or relationships with colleagues, presented in this critical review.

Bailey et al. (2001) mentioned seven professional development activities that teachers can practice to enhance their performance regarding professional development protocols. The practices include writing teaching journals, video-taping, co-teaching, mentoring, teaching, and conducting action research. These pedagogic exercises contribute to raising self-awareness and self-observation of both pre-and in-service teachers. Amongst the methods above, peer observation of teaching has long been a trusted and transformative tool to assess teachers' performance over the world (Bell \& Mladenovic, 2008) and in Vietnam (Cao, 2019; Do, 2012). Although there is a large body of literature about the benefits of peer observation of teaching, there are concerns regarding the creditability, reliability, accountability, and applicability of this protocol on teacher professional development (Hammersley-Fletcher \& Orsmond, 2004; Putnam, 1985). These concerns are even more noticeable in the current era when teachers start to be more flexible in teaching strategies rather than following specific methods with pre-determined sets of procedures (Nguyen \& Bui, 2020; Ping, 2005). The liberating teaching and learning trend makes the teaching procedures even harder to assess as peer-observation becomes more developmental than appraisal (Lam, 2001). Since professional development has started to regain attention in the researcher' s world recently (Hung \& Baranovskaya, 2020), it is noteworthy to re-investigate how peer observations are conducted these days and how teachers perceive the merits and demerits of peer observation. Furthermore, it is also important to point out the criteria worth considering to 
enhance peer observation of teaching in the classroom. Therefore, this critical review seeks to investigate three questions: (1) What are the current practices of peer observation of teaching in the world?; (2) What are some perceived benefits and limitations of peer observation of teaching in EFL Classrooms?; (3) What are some solutions to foster peer observation as a teacher professional development protocol?

This review investigates the existing literature to draw out an overall picture of peer observation, its benefits, and limitations in teachers' professional development in the world. After introducing the purpose of this paper and discussing fundamental concepts, the author continues to describe the models of peer observation that are being implemented in the world. Then, the author would synthesize the pros and cons of peer observations, followed by a discussion of how to face the criticisms against peer observation of teaching. This paper also proposes pedagogical implications for institutions and the teaching staff to follow. To conclude the review, the author presents research gaps as directions for further studies on peer-observation of teaching as a professional development protocol.

\section{LITERATURE REVIEW}

\subsection{Definition and Focus}

According to Blanchett et al. (2018), peer observations take place when a fellow teacher observes another teacher's class, after which some feedback is exchanged orally or in the form of a written report. The investigation of literature reveals that while the traditional purpose of peer-observation used to focus only on the evaluation and assessment of teachers, peer-observation has currently transformed into a reflective, developmental, and collaborative process (Day, 2015; Gosling, 2014; Gosling \& Mason, 2009; Peel, 2005). Likewise, Shortland (2004) believed that peer observation does not only include observing colleagues in the classroom but is also a process through which self-learning can occur. According to Hammersley-Fletcher and Orsmond (2005), peer observation is the instrument in developing teachers' reflective practices. In this review, peer observation is an eclectic protocol that serves three different purposes according to the different specific teaching contexts: (1) Evaluate the teacher's performance; (2) Monitor and facilitate professional development of novice teachers; (3) Foster collaborative professional development through exchanges of experience and discussion.

This paper's foci are on the second and the third functions although the evaluative function will be briefly discussed as a vital part of peer observation.

\subsection{Conceptual Models of Peer Observation}

Literature in teaching training suggests that peer observation takes place in different models (Gosling, 2002, 2014; Gosling \& Mason, 2009). There are three categories of peer observation: evaluative, developmental, and collaborative (Gosling, 2002). As its observation's outcome is evaluative or descriptive, the evaluation model is a management model that will benefit the institution. On the other hand, a more experienced teacher, an education developer, or a headmaster will observe the less experienced teacher during a developmental observation section, which is similar to mentorship. This type of observation focuses on the development of the novice teacher's teaching abilities or the assessment of competence for recruiting purposes. Byrne et al. (2010) modified Gosling's (2002) models by including the peer-developmental model as a model that emerges from peer-reviewed observation. However, both models cannot address all the current models that are in practice, especially newly emerged models in the form of teacher training practices.

\section{MATERIALS AND METHODS}

This article is written in the form of a critical review that presents, analyzes, and synthesizes materials from various sources. Following SALSA frame by Grant and Booth (2009), this critical review underwent four main stages: searching, appraisal, synthesis, and analysis. The author started by searching the most significant items in peer-observation of teaching based on the author's experience. While the process of choosing materials in a critical review does not require a formal quality assessment, the author attempted to evaluate the input material according to their contribution to the field. Therefore, primary, secondary and tertiary sources of references were exploited in this project. Online research networks such as Scopus, Google Scholars, and Web of Science were the three primary sources where the author initiated the further process to investigate and collect suitable peer-reviewed articles as the primary source of information for this article. While peer-reviewed research articles account for a high percentage of this review, the author also used books on teacher professional development, for example, Pursuing professional development: The self as source (Curtis et al., 2001) and other related materials available such as reports or conference proceedings where necessary. In the synthesis stage, the author applied both narrative and chronological approaches to consider the new contribution to models of peer observation around the world and figured out the gaps in those models. Finally, in the analyzing stage, the author grouped the information found into significant components 
to revise more up-to-date and more full-coverage models of observation, investigate perceived benefits and limitations, and propose solutions according to theoretical themes.

\section{RESULTS AND DISCUSSION}

\subsection{Contemporary Peer Observation Models in Practice}

Gosling(2002) believed that the evaluative model (Column A) is also the management model that will benefit the institution as the observation's outcome is judgmental or descriptive. Within this model, 'power' is the mere aspect that determines the relationship between the observers and the observed staff. The institutions may utilize this model in their appraisal, promotion, or teacher assessment process (Carroll \& Loughlin, 2013). As the observation of teaching as an evaluative means aims at appraisal or promotional purposes, they are usually single shots rather than a continuous linear. On the other hand, developmental observation (Column B) resembles a form of mentoring in which a more experienced teacher, an education developer, or a headteacher will observe the less experienced teacher (Gosling, 2014). This form of observation focuses on developing the novice teacher's teaching ability or testing their competencies for recruitment. The developmental observation can also occur when a teacher is underperforming and needs monitoring.

However, the initial model by Gosling (2002) fails to include the reversed version of the developmental model that takes place contemporarily in many countries such as Vietnam or the United States. Within this reversed model, an expert teacher gives a demonstration lesson, and the novice/preservice teachers observe (Column C). This form of observation is of demonstrative purpose for the novice teacher(s) to gain more experience from the observed teacher. In a demonstrative observation section, the observed teacher functions as an experienced facilitator. At the same time, the observers are the guest teachers who are willing to learn and connect to the observation experience (New York State Education Department, 2014). This observation model may also include instructional coaches or program department consultants working closely with the demonstrating teachers to help the observers (Grierson \& Gallagher, 2009). While the observed teachers may gain creditability for their expertise, this form of observation emphasizes the development of novice teachers. As they observe the lesson, they can extend their teaching repertoire, transfer suitable methods to practice, learn the program content, and contribute feedback to the demonstrative teacher (Putnam, 1985).

Previously, it is also argued that there should be an emphasis on collaborative peer observation, for this model is more encouraging in terms of mutual development, non-judgmental, more autonomous, and more dialogic (Sachs \& Parsell, 2014). This observation form is a ground on which other peer-observation models develop, including the peer-reviewed and peer-supported/ peer-developmental observation model (Purvis et al., 2009) (Column D). However, peer-reviewed observation has a significant limitation as it may become unfocused at times (Gosling, 2002). Byrne et al. (2010) adapted the models suggested by Gosling (2002), adding the peer-developmental model as a model that evolves from the peer-reviewed observation (Column E). They claimed that this model allows the teachers to identify the aspects of mutual interest and focus on other aspects besides traditional teaching practices. There are three noticeable differences between peer-reviewed and peer-developmental observation as a peerdevelopmental observation: (1) Allow the professional development to happens through exploratory dialogues in addition to the observation sections; (2) Allow the teachers to specify what aspects they should focus on instead of reviewing all the aspects of teaching; (3) Open to a broader scope of interest beyond teaching practices.

Table 1. Models of peer-observation (adapted from Gosling (2002) and Byrne et al. (2010))

\begin{tabular}{|c|c|c|c|c|c|}
\hline & $\mathbf{A}$ & B & $\mathbf{C}$ & D & $\mathbf{E}$ \\
\hline Characteristics & Evaluative & Developmental & Demonstrative & Peer-reviewed & $\begin{array}{c}\text { Peer- } \\
\text { developmental }\end{array}$ \\
\hline Focus & $\begin{array}{l}\text { Institutional } \\
\text { interest }\end{array}$ & $\begin{array}{l}\text { Observed } \\
\text { teachers }\end{array}$ & Observers & Mutual interest & Mutual interest \\
\hline Channels & $\begin{array}{l}\text { One-sided } \\
\text { (senior staffs } \\
\text { observe other } \\
\text { staff) }\end{array}$ & $\begin{array}{l}\text { Usually one- } \\
\text { sided } \\
\text { (educational } \\
\text { developers/exper } \\
\text { t teachers } \\
\text { observe other } \\
\text { teachers) }\end{array}$ & $\begin{array}{l}\text { Usually one- } \\
\text { sided/ } \\
\text { Can be two- } \\
\text { sided when } \\
\text { feedback is } \\
\text { exchanged }\end{array}$ & $\begin{array}{l}\text { Multi/ two-sided } \\
\text { (through teacher } \\
\text { observation) }\end{array}$ & $\begin{array}{l}\text { Multi/ two-sided } \\
\text { (through } \\
\text { observation and } \\
\text { exploratory } \\
\text { dialogues about } \\
\text { shared areas of } \\
\text { practices) }\end{array}$ \\
\hline
\end{tabular}




\begin{tabular}{|c|c|c|c|c|c|}
\hline & & & $\begin{array}{l}\text { (novice teachers } \\
\text { observe expert } \\
\text { teachers) }\end{array}$ & & \\
\hline $\begin{array}{l}\text { Relationship } \\
\text { axis }\end{array}$ & Authority & Expertise & $\begin{array}{l}\text { Expertise/ } \\
\text { mentoring }\end{array}$ & $\begin{array}{l}\text { Equality/ } \\
\text { mutuality }\end{array}$ & $\begin{array}{l}\text { Equality/ } \\
\text { mutuality }\end{array}$ \\
\hline Outcome & $\begin{array}{l}\text { Report/ } \\
\text { judgment }\end{array}$ & $\begin{array}{l}\text { Report/ action } \\
\text { plan } \\
\text { Fail/ pass }\end{array}$ & $\begin{array}{l}\text { Report/action } \\
\text { plan/ reflection, } \\
\text { discussion }\end{array}$ & $\begin{array}{l}\text { Analysis, } \\
\text { discussion, } \\
\text { wider experience } \\
\text { of teaching } \\
\text { methods }\end{array}$ & $\begin{array}{l}\text { Analysis, } \\
\text { discussion, } \\
\text { wider experience } \\
\text { of areas of } \\
\text { practices }\end{array}$ \\
\hline Frequency & Summative & $\begin{array}{l}\text { Summative/ } \\
\text { formative }\end{array}$ & $\begin{array}{l}\text { Summative/ } \\
\text { formative }\end{array}$ & Formative & Formative \\
\hline $\begin{array}{l}\text { Status of } \\
\text { evidence }\end{array}$ & Authority & Expert diagnosis & $\begin{array}{l}\text { Experience/ } \\
\text { expert guidance }\end{array}$ & $\begin{array}{l}\text { Peer shared } \\
\text { perception }\end{array}$ & $\begin{array}{l}\text { Peer shared } \\
\text { perception }\end{array}$ \\
\hline Confidentiality & $\begin{array}{l}\text { Between the } \\
\text { management, the } \\
\text { observer, and the } \\
\text { observed }\end{array}$ & $\begin{array}{l}\text { Observer and the } \\
\text { observed, } \\
\text { examiner and } \\
\text { examinee }\end{array}$ & $\begin{array}{l}\text { The observer, } \\
\text { the observed, } \\
\text { and the } \\
\text { instructional } \\
\text { coaches }\end{array}$ & $\begin{array}{l}\text { Between the } \\
\text { observer and the } \\
\text { observed }\end{array}$ & $\begin{array}{l}\text { Partner } \\
\text { colleagues }\end{array}$ \\
\hline
\end{tabular}

\subsection{The Perceived Benefits of Peer Observation among Teachers}

There has been an extensive body of literature investigating peer observation benefits, especially the contemporary peer-supported/ collaborative model for both in-service and preservice teachers (Day, 2015; Do, 2012; Yon et al., 2002). The first benefit is the improvement in terms of both subject-matter knowledge and pedagogic content. Besides, peer-observation sessions can initiate the reflective process among teachers (Day, 2015). Peel (2005) described her own experience with peer observation, considering it an opportunity to reflect on the substantive knowledge. Besides, peer observation of teaching heightened her awareness of physical presence in the classroom. Another study by Kohut et al. (2007) also concluded that peer observation could familiarize teachers with the course's disciplinary content. This is in line with Putnam's (1985) table of perceived benefits of peer observation. However, teachers may prefer more feedback on the pedagogic strategies that they use in class. Day (2015) showed that the student-teachers who took part in peer-observation realized they should reduce teacher talking time and the cliché that teachers usually use such as good, well-done, or excellent. They could also learn each other's strategies as well as getting inspired by others' passion. By watching other teachers, observers can get new ideas and reflect on their teaching (Bell \& Mladenovic, 2008). The study by Bell and Mladenovic (2008) concluded that evaluative and developmental peer observation work is accompanied by collaborative peer observation since it makes the teachers focus consecutively on the student's experience of the tutorial, the reflective practice, and assessment. Another benefit is the de-isolating effect peer-observation brings about (Bailey et al., 2001). Forty-eight percent of the teachers who participated in a survey by Adshead et al. (2006) agreed that peer-observation could have de-isolating effects on teachers. In the study, even when some teachers did not feel isolated in the first place, peer observation of teaching gave them a greater sense of connection to the teaching community.

\subsection{Concerns Related to Peer Observation of Teaching}

There are many concerns related to peer observation, from a managerial scale to a personal scale. First, a lack of trust in the observed novice teachers' ability may discourage the observers from receiving the mutual benefits necessary for the development of the teaching staff (Day, 2015). It is also noteworthy to address the teaching staff's challenges to specify what good teaching practices are. Even when a vast body of literature sought to list characteristics determining good teaching practice, many of them are high interference (Ramsden, 2002). These high interference characteristics are significantly subjective or even unobservable.

Consequently, this provokes doubts regarding the validity of teaching observation if it is linked to the institutional or departmental decision-making process (Kohut et al., 2007; Rinehart, 1993). Even when there are characteristics to describe a teacher's performance, the stability of their performance and effects on student academic performance is very low (Good \& Lavigne, 2015; Konstantopoulos, 2014; Morgan et al., 2014). The performance of a teacher is under the influence of many different aspects related to the classroom contexts. Therefore, summative observation 
sessions can coincide with the teacher performance's parachute drop, which may demotivate and inappropriately assess their teaching performance (Stodolsky, 1984; Yon et al., 2002).

There are also concerns about the formalization and the institutionalization of some aspects of the peerobservation process, for example, the discussion part (Purvis et al., 2009). This problem becomes more significant when there is a lack of institutional support and training because of the limited time allocation (Kohut et al., 2007). Additionally, many teachers attend the observation sessions unwillingly because it is merely the institutional policy rather than a real benefit. Deeming the peer observation process unauthentic (Santos, 2016), the observers may believe that they cannot benefit from others' teaching practices. In order words, peer-observation is usually onesidedly beneficial (Gosling, 2014).

The teachers also have a problem with being polite and giving constructive feedback as they do not have a structured process to follow. They are afraid of losing face and confronting their colleagues in terms of expertise (Bailey et al., 2001). As peer observation may be face-threatening, teachers also raise questions about avoiding Hawthorne effect or the observer's paradox (Thampy \& Kersey, 2015). Indeed, it is common for workers, particularly teachers, to alter their behaviors compared to their daily practices when they are under observation (Rosenthal et al., 2009). In brief, there are six main concerns about peer observation: (1) Validity; (2) Formalization and institutionalization; (3) Willingness and mutual interest; (4) Politeness and confrontation; (5) The stability of teacher performance; (6) Hawthorne effect.

\subsection{Facing the Challenges of Peer Observation of Teaching \\ 4.4.1. Duration and Frequency}

Peer observations can be either a summative assessment or a formative sequence of observations in terms of duration and frequency. According to O'Leary (2012), summative peer observation is the snapshot approach to observation. Yon et al. (2002) claimed that summative peer observation may lead to a biased decision if the observed teacher is in his/her 'parachute drop'. This problem heightens when teachers undergo evaluative peer observation sessions, which puts them under institutional or departmental pressure.

Peer observation should reflect teachers' professional formative and developmental growth (Drew et al., 2017) while summative peer observation can only address the performance of a teacher at an isolated point in time. Moreover, formative peer observation can yield benefits when teachers need to familiarize themselves with various teaching situations to reach their professional goals (Knight et al., 2006). In sharp contrast, summative observation cannot thoroughly investigate the development of the teachers. Besides, formative peer observations can usually evoke more supportive feedback and constructive comments as the observer have to follow up after their initial session rather than solely give feedback (Lomas \& Nicholls, 2005). This continuation of observation and experience exchanges can foster the culture of criticisms in the feedback-giving process (Amrein-Beardsley \& Popp, 2012).

All in all, formative peer observation sessions can function more effectively in comparison with summative sessions as they can (1) address the continuity of teacher professional development process, (2) allow both observed and observing teachers to acclimatize with different teaching situations that enlarge their teaching knowledge repertoire, and (3) contribute to a more civilized culture of giving and receiving observation feedback. In other words, the formative peer observation of teaching can be the solution to teacher performance instability. Therefore, instead of implementing peer observation as a summative activity, the school faculty should conduct repeated peer observations or formative peer observation of teaching (Yon et al., 2002).

\subsubsection{The Win-Win Situation}

Some studies claim that observation sessions will benefit only the less experienced teachers observed (Byrne et al., 2010; Gosling \& Mason, 2009). However, opposing studies on teachers' perception show that, while the focus is on the novice teachers, the expert teachers themselves notice that they also improve their teaching through the reflection of their observation (Ahmed et al., 2018; Kohut et al., 2007). As the expert teachers will observe and comments on the less experienced teachers (Gosling \& Mason, 2009), the observers usually take on the roles of guiding and improving the observee's development and additionally helping them improve their teaching practices by reminding themselves of how they have developed through times. Kohut et al. (2007) conducted a study with 530 teachers using two different survey sets to explore their perception of peer observation. In this study, Kohut et al. noticed that the observers even felt peer observation improved their teaching more than the observation. Therefore, the relationship between the observers and the observed staff based on their expertise can be reciprocal (Richards \& Lockhart, 1991). 
The application of collaborative peer observation of teaching can further foster the balance in interests between both the observers and the observed teachers. In Thampy et al. (2015), 25 peer-review observation sessions took place within 12 months. After these sessions, the participants reported feeling the mutual benefits inherent in this observation form. The teachers believed that they could share their experience to curb isolation and learn from other teachers how to handle the classroom. This mutual benefit also takes place in the study of Mento and GiampetroMeyer (2000). Collaborative peer observation of teaching can also work in the appreciative inquiry framework (Fileborn et al., 2020). In the form of a peer-developmental observation, this framework suggests that the focus of the reviews of teaching should focus on each other's strengths to understand, anticipate, and unearth the hidden potential within their teaching practices. According to Byrne et al. (2010), the friendly and non-judgmental environment that peer-developmental reviews of teaching create through dialogues and conversations makes the teacher feel the process more meaningful and essential. The teachers in the interviews also believed that the collegiate nature of peer-developmental observation allows them to develop as a group rather than as an individual. In other words, this collegiality can create both trust and mutual ownership of teacher's professional development in an institution.

\subsubsection{The Self-Selected Observer: A Critical Friend}

It is believed that the observation partners should be 'critical friends' as the observation process should rely on trust, mutual respect, and meaningful reflection-on-action (Farrell, 2001; Shortland, 2010). Francis (2001) claimed that there is little attention paid to the complexity of interpersonal communication in peer observation. This lack of communication may stem from the fear of losing face, bringing about hesitation and non-compliance in the early period of peer-observation process (Shortland, 2010). Therefore, the selection of observation partners may, in turn, curb the problems related to politeness and confrontation as well as Hawthorne effects. Teachers can feel more relaxed if they have built a good rapport with their observation partners (Hendry \& Oliver, 2012).

Regarding the evaluative nature of observations that constitute the appraisal process, there must be a transparent and unbiased judgment of teacher's performance. Hence, the random pairing of observers and observers who have a neutral working relationship by the management may be appreciative and appropriate. However, a self-selected partner may yield more benefits when it comes to teacher professional development. Exploratory qualitative research by Carroll and Loughlin (2013) investigated motivations, challenges, and outcomes of 10 first-time peer-observation users in Higher Education institutions in Ireland. The study concluded that self-selected partners might increase the level of negative feedback endurance. The self-selected partners bring about comfort, and the participants felt that the criticism would be confidentially treated among the observers and the observes themselves. Besides, self-selected partner selection can also prevent confrontation and allow both parties to exchange constructive criticisms feeling defensive. Bell and Mladenovic (2008) also adopted the same approach in their study to increase the collegiality and confidentiality of the peer observation process. This is in line with the suggestion proposed by Shortland (2004), stating that informal collegiality can be more fruitful in teacher professional development.

While self-selected partners may help limit peer observations' adverse face-threatening effects, participants need to be careful with their choice. The teachers participating in Carroll and Loughlin's (2013) research claimed that it was challenging for them to strike a balance between politeness and openness. Noticeably, some observers were also under departmental pressure to give positive feedback if the observation results are related to the judgmental and assessment purposes of their friends or colleagues. Shorthand (2010) warned that some productive relationships between peers can be jeopardized in the case of conflicts of interest within the process of peer observation. Therefore, it is recommended that if the peer-observation of teaching is for the sake of the departmental or institutional evaluation, random pairing should be prioritized.

4.4.4. The Professional Dialogue: Formal or Informal?

Gosling (2014) claimed that dialogue-based peer-developmental observation is paramount to help teachers overcome the pedagogic assumptions that teachers usually take for granted. Rather than focusing only on either the observers or the observed teachers, the application of peer-reviewed and peer-developmental observation can bring about the conversations and dialogues that liberate the teachers and allow them to voice their opinion about teaching practices (Brookfield, 2005).

The feedback session can be informally arranged among the teachers to discuss whatever areas they think they should focus on. The feedback session can also be a compulsory formal session in which teachers have to follow the strict guidelines of the institution. A study showed that institutionalized feedback is suitable for evaluative purposes (Mento \& Giampetro-Meyer, 2000). These formal feedback sessions can prompt teachers to speak more and 
seriously consider peer observation of teaching as a part of their actual professional development (Purvis et al., 2009). Also, formal feedback is more suitable and time-saving if the observation group has more than two members, particularly if it demonstrative observation where one experienced teacher mentors novice teachers. Additionally, formal feedback sessions are also beneficial if the teachers have limited experience with peer observation or are unwilling to work with a peer through self-reflection (Gosling, 2014).

On the other hand, while some institutions consider formalizing the feedback exchange and discussion, the teachers participating in the study by Purvis et al. (2009) believed that this could bureaucratize the professional development process. They claimed that discussion revolves around their teaching practices could have been kept informal. This informality preference is in line with the idea that professional development should rely on informal and non-formal learning to identify the gaps that cannot be revealed by informal learning (Misko, 2008). Although informal learning is invisible, it is a part of the developmental process, especially when initiated as a part of the learning's choice (Callanan et al., 2011; Eraut, 2004). In a case study by Shortland (2010), informal conversations between the observers and the observed teacher strengthen the trust and deepen the understanding between them. The informality of the professional dialogues creates an atmosphere that is less stressful and more conducive to development (Hammersley-Fletcher \& Orsmond, 2004). From the studies' results, the author suggests the following table of feedback sessions suitable for each peer observation model (Table 2).

Table 2. Suggested types offeedback sessions

\begin{tabular}{ccccc}
\hline Evaluative & Developmental & Demonstrative & Peer-reviewed & $\begin{array}{c}\text { Peer- } \\
\text { developmental }\end{array}$ \\
\hline formal & formal $\rightarrow$ informal & formal & informal & informal \\
\hline
\end{tabular}

Feedback should be formal for an evaluative session as transparency is required, especially if the observation is for appraisal purposes such as promotion or salary consideration. On the other hand, developmental observation, in which an expert observer gives training to a less experienced observed teacher, should start as formal sessions to familiarize the observed with the process and foci of their teaching procedures. After that, as novice teachers develop, the feedback session becomes less formal to reduce pressure and save time. Likewise, for demonstrative peer observation, the feedback exchange should also be formal to channel a larger audience as there is usually one experienced teacher who will demonstrate what they do in class to the group of guest teachers. In sharp contrast, as regards peer-reviewed and peer-developmental observations, the feedback session should be informal as the outcome of the process focuses on the teacher's development rather than a departmental report. The formative nature of these collaborative observations would make formal discussions time-consuming and bureaucratic. Instead, short informal but focused exchange would allow the teachers to reflect on the specific areas to initiate changes with more minor degrees of interval.

\subsubsection{Hawthorne Effect}

Theoretically, Hawthorne effect is a phenomenon when the participants' awareness in an experiment, created by the experiment conditions, interacts with the independent variables and subsequently facilitates the effects on the dependent variables, thus leading to ambiguous results (Cook, 2015). Regarding education, Hawthorne effect happens when the experimental or observation environment changes the participants' (teachers and students) behaviors. In other words, the behaviors change when the teachers and students know that they are observed. Not all researchers agree with the existence of Hawthorne effect. Franke and Kaul (1978), Jones (1980), and Wickstrom and Bendix (2000) believed that Hawthorne effect is insignificant and controversial or hard to happen in different contexts. Levitt and List (2011) failed to replicate the original study that confirmed Hawthorne effect's existence. Therefore, whether Hawthorne effect occurs in peer observation of teaching requires further research. A study by Thampy et al. (2015) showed the mixed findings of Hawthorne effect. In this study, while some teachers changed their behavior to include the observers in their lessons, others refrained from acting differently from what they usually did.

Assuming that Hawthorne effect exists and wears off with time (Leonard \& Masatu, 2006), peer observation should be a formative process so that after several sessions, the observation can reflect teachers' actual behaviors (Evans, 2014). In sharp contrast, Cook (2015) claimed that Hawthorne effect is consistent over time. In this case, the author suggests that formative collaborative observation, the observer's self-choice, and informal feedback sessions can allow the observed teachers to start in their comfort zone and express themselves more freely. In brief, whether Hawthorne effects in peer observation of teaching is a fundamental matter to consider or just a myth still needs further 
investigation. However, teachers can take on peer observation of teaching with more comfort and willingness with the aforementioned strategies.

\subsection{Pedagogical Recommendations and Research Gaps}

As teaching becomes more eclectic, the purposes and function of peer observation of teaching also evolve. Rather than focusing exclusively on the evaluative nature, peer observation of teaching is now implemented mainly in five different models: evaluative, developmental, demonstrative, peer-reviewed, and peer-developmental. While different models suit different needs and specific teaching and learning contexts, this critical review theoretically supports developmental collaborative peer observation as it contributes to the teacher's development in various aspects. Technically, developmental collaborative peer observation can reduce fear, balance mutual interest, and reduce the observer effects.

School and institution administrators should come to terms with the eclectic nature of teaching in the new areas, thus allowing flexibility in the observation process. In the foreseeable future, it is suggested that even when the observation is for assessment purposes, there should still be room for teachers to move from conventional teaching steps. The school management should advocate developmental collaborative peer observation, allowing teachers to focus on their topics of concern. These topics do not need to be limited to teaching practices but can be about other areas of professional development. In the long run, the leaders of institutions should create and foster a professional community network where teachers can pair and participate in different peer observation types. The schools should also provide teachers with basic guidelines for conducting peer observation; however, the teacher should be informed that the observational experience should go beyond what is written in the documents (Gosling \& Mason, 2009). These communities can be the platform for teachers to share their reflection-on-teaching or conduct action research.

Teachers should participate in peer observation as a reflective, collaborative, and developmental process. Moreover, teachers should distinguish between summative and formative peer observation. For formative observation, the goal is to develop their professional skills, not to judge or assess. Therefore, when practicing formative peer observation, teachers should behave as they usually do rather than put on a pretense to please the observer (Evans, 2014). If they are allowed to select their observational partner, teachers should point out particular areas they want to focus on and conduct the observation. When attending to other teachers' observations, teachers should be objective as a 'critical friend' rather than avoid conflicts (Megawati, 2018; Thampy \& Kersey, 2015). They should also avoid comparing their teaching styles with other teachers but rather reflect on ideas, strategies, and approaches to teaching as different teaching contexts require different sets of skills.

Although there is a shift from using peer observation as an evaluative tool to a professional development protocol, most research works are small-scale and localized. There is a call for more empirical research on the effectiveness of peer observation in professional development. Research has mainly focused on teachers' perception; however, other aspects, such as the effects of peer observation on value-added academic measures or class management, are also worth consideration. There should also be research on how students perceive themselves as a part of the observation. As mentioned above, there is still limited research into other psychological aspects related to peer observation of teaching, such as the Hawthorne effect and teacher comfort zone, which opens up more in-depth studies. Additionally, although the author does not advocate the use of peer observation as the only evaluative tool for appraisal, future research can also investigate what aspects should be focused on in other to assess the teacher's performance more objectively and accurately. The effectiveness of the application supporting tools and devices such as an audio recorder or video recorder to reduce observation anxiety, fear, and stress can also be investigated. Besides, the development of computer-assisted teaching and learning and the outbreak of Covid-19 increase the demand for online learning and teaching flipped classrooms and blended learning. This new learning trend may require a search for other approaches to peer observation, which is another potential area for research.

\section{CONCLUSION}

This critical review investigates five different models currently popular in the world: evaluative, developmental, demonstrative, peer-reviewed, and peer-developmental. Subsequently, the author analyzes the merits of the peer observation of teaching, which benefit the understanding of disciplinary content and pedagogic strategies, initiate and maintain reflection of teaching practices, and de-isolate teachers. On the other hand, the article also reviews six main concerns related to peer observation of teaching, ranging from the duration, validity, the choice of observational partner, formality, and other psychological aspects. While it is virtually impossible to thoroughly outline all the concerns and criticism against peer observation of teaching, the author evaluates what aspects practitioners of peer observation should prioritize. Careful choices of conducting peer observation should be made according to each 
specific teaching context rather than strictly follow cut-and-dried procedures so that peer observation is truly a blessing in professional development.

\section{REFERENCES}

Adshead, L., Patrick, T. W. \& Anne, S. (2006). Introducing Peer Observation of Teaching to GP Teachers: A Questionnaire Study. Medical Teacher, 28(2), 68-73. https://doi.org/10.1080/01421590600617533

Ahmed, E., Zaimuariffudin, S. N., Sayyed R. S. \& Mansoor, A. C. (2018). Peer Observation: A Professional Learning Tool for English Language Teachers in an EFL Institute. World Journal of Education, 8(2), 73-87. https://doi.org/10.5430/wje.v8n2p73

Amrein-Beardsley, A. \& Sharon, E. O. (2012). Peer Observations among Faculty in a College of Education: Investigating the Summative and Formative Uses of the Reformed Teaching Observation Protocol (RTOP). Educational Assessment, Evaluation and Accountability, 24(1), 5-24.

Bailey, K. M., Andy, C. \& David, N. (2001). Pursuing Professional Development: The Self as Source. Boston, Massachusetts: Heinle .

Bell, A. \& Rosina, M. (2008). The Benefits of Peer Observation of Teaching for Tutor Development. Higher Education, 55(6), 735-752. https://doi.org/10.1007/s10734-007-9093-1

Blanchett, H., Chris, P. \& Jo, W. (2018). Peer Observation. A Guide to Teaching Information Literacy.

Borko, H. (2004). Professional Development and Teacher Learning: Mapping the Terrain. Educational Researcher, 33(8).

Brookfield, S. D. (2005). The Power of Critical Theory: Liberating Adult Learning and Teaching. Maidenhead: Open University Press.

Bush, J. E. (2007). Importance of Various Professional Development Opportunities and Workshop Topics as Determined by In-Service Music Teachers. Journal of Music Teacher Education, 16(2), 10-18.

Byrne, J., Hazel, B. \& Doreen, C. (2010). Peer development as an alternative to peer observation: A tool to enhance professional development. International Journal for Academic Development, 15(3), 215-228. 10.1080/1360144X.2010.497685

Callanan, M., Christi, C. \& Molly, L. (2011). Informal Learning. Wiley Interdisciplinary Reviews: Cognitive Science., 2(6), 646-655.

Cao, P. (2019). Developing Pedagogical Skills Through Time Attendance - From Reflecting on Teaching to Effective Teaching. Ho Chi Minh City University of Education Journal of Science, 16(8), 253-263.

Carroll, C. \& Deirdre, O. L. (2013). Innovations in Education and Teaching International Peer Observation of Teaching: Enhancing Academic Engagement for New Participants, 37-41.

Cook, D. L. (2015). The Hawthorne Effect in Educational Research. The Phi Delta Kappan, 44(3), 116-122. Published By: Phi Delta Kappa International.

Day, R. (2015). Peer Observation and Reflection in the ELT Practicum. Journal of Language and Literature Education, 52, 1-8.

Do, T. P. T. (2012). Beginning Teachers' Observation of Peers - The Values, Limitations, and Suggestions from the Perspectives of the Insiders. University of Foreign Languages and International studies.

Drew, S., Liam, P., Katherine, L., Angela, C., Bella, R., Kayleen, W., Susan, S., \& Caroline, C. (2017). Formative Observation of Teaching: Focusing Peer Assistance on Teachers' Developmental Goals. Assessment and Evaluation in Higher Education, 42(6), 914-929. https://doi.org/10.1080/02602938.2016.1209733

Eraut, M. (2004). Informal Learning in the Workplace. Studies in Continuing Education.

Evans, D. (2014). The Hawthorne Effect: What Do We Really Learn from Watching Teachers (and Others)? Impact Evaluations. The World Bank. Retrieved from https://blogs.worldbank.org/impactevaluations/hawthorne-effectwhat-do-we-really-learn-watching-teachers-and-others

Farrell, T. S. C. (2001). Tailoring Reflection to Individual Needs: A TESOL Case Study. Journal of Education for Teaching, 27(1), 23-38

Fileborn, B., Mark, W. \& Claire, L. (2020). Peer Reviews of Teaching as Appreciative Inquiry: Learning from 'the Best' of Our Colleagues. Higher Education. https://doi.org/10.1007/s10734-020-00637-9

Francis, D. (2001). The Challenge of Involving Students in the Evaluation Process. Asia-Pacific Journal of Teacher Education, 29(2), 125-137. 
Franke, R. H. \& James, D. K. (1978). The Hawthorne Experiments: First Statistical Interpretation. American Sociological Review.

Good, T. \& Alyson, L. (2015). Issues of Teacher Performance Stability Are Not New: Limitations and Possibilities. Education Policy Analysis Archives, 1-16.

Gosling, D. (2002). Models of Peer Observation of Teaching Co-Director, Teaching Quality Enhancement Fund National Co-Ordination Team. LTSN Generic Centre (August).

Gosling, D. (2014). Collaborative Peer-Supported Review of Teaching. Peer Review of Learning and Teaching in Higher Education: International Perspectives.

Gosling, D. \& Mason, O. (2009). Beyond the Peer Observation of Teaching. SEDA paper, 124.

Grant, M. J., \& Booth, A. (2009). A typology of reviews: An analysis of 14 review types and associated methodologies. Health Information and Libraries Journal, 26(2), 91-108. https://doi.org/10.1111/j.14711842.2009.00848.x

Grierson, A. L. \& Tiffany, L. G. (2009). Seeing Is Believing: Creating a Catalyst for Teacher Change through a Demonstration Classroom Professional Development Initiative. Professional Development in Education, 35(4), 567-584.

Guskey, T. R. (2002). Professional Development and Teacher Change. Teachers and Teaching: Theory and Practice.

Hammersley-Fletcher, L. \& Paul, O. (2004). Evaluating Our Peers: Is Peer Observation a Meaningful Process?. Studies in Higher Education, 29(4), 489-503.

Hammersley-Fletcher, L. \& Paul, O. (2005). Reflecting on Reflective Practices within Peer Observation. Studies in Higher Education, 30(2), 213-224.

Hendry, G. D. \& Gary, R. O. (2012). Seeing Is Believing: The Benefits of Peer Observation. Journal of University Teaching \& Learning Practice, 9(1).

Hung, B. P. \& Tatiana, A. B. (2020). Second Language Teaching and Teacher Education in Diverse Contexts. Journal of Language and Education, 6(3), 4-6.

Jenkins, J. M., Alex, G. \& Patience, J. (2005). Preservice Teacher Observations in Peer Coaching. Journal of Teaching in Physical Education, 24(1), 2-23.

Jones, S. R. G. (1980). Was There a Hawthorne Effect?. Administrative Science Quarterly, 25(4), 654.

Knight, P., Jo, T. \& Mantz, Y. (2006). The Professional Learning of Teachers in Higher Education. Studies in Higher Education, 31(3), 319-339. https://doi.org/10.1080/03075070600680786

Kohut, G. F., Charles, B., and Maria, G. Y. (2007). Peer Observation of Teaching: Perceptions of the Observer and the Observed. College Teaching, 55(1), 19-25.

Konstantopoulos, S. (2014). Teacher Effects, Value-Added Models, and Accountability. Teachers College Record, 116(1).

Lam, S. F. (2001). Educators' Opinions on Classroom Observation as a Practice of Staff Development and Appraisal. Teaching and Teacher Education, 17(2), 161-173. https://doi.org/10.1016/S0742-051X(00)00049-4

Leonard, K. \& Melkiory, C. M. (2006). Outpatient Process Quality Evaluation and the Hawthorne Effect. Social Science and Medicine, 63(9), 2330-2340. https://doi.org/10.1016/j.socscimed.2006.06.003

Levitt, S. D. \& John, A. L. (2011). Was There Really a Hawthorne Effect at the Hawthorne Plant? An Analysis of the Original Illumination Experiments. American Economic Journal: Applied Economics, 3(1), 224-238.

Lomas, L. \& Gill, N. (2005). Enhancing Teaching Quality through Peer Review of Teaching. Quality in Higher Education, 11(2), 137-149.

Megawati, F. (2018). Peer Observation of Teaching: Preservice Teachers' Perspectives for Better Performance. Atlantis Press.

Mento, A, J. \& Giampetro-Meyer, A. (2000). Peer Observation of Teaching as a True Developmental Opportunity. College Teaching, 48(1), 28-31.

Misko, J. (2008). Combining Formal, Non-Formal and Informal Learning for Workforce Skill Development. National Centre for Vocational Education Research NCVER, 45.

Morgan, G. B., Kari, J. H., Tonya, M. T. \& Lorin, W. A. (2014). The Stability of Teacher Performance and Effectiveness: Implications for Policies Concerning Teacher Evaluation. Education Policy Analysis Archives.

New York State Education Department (2014). Demonstration Classroom Guidance Document. New York.

Nguyen, Q. N. \& Hung, P. B. (2020). The Dogme Approach: A Radical Perspective in Second Language Teaching in the Post-Methods Era.Journal of Language and Education, 6(3),173-184. 
O'Leary, M. (2012). Exploring the Role of Lesson Observation in the English Education System: A Review of Methods, Models and Meanings. Professional Development in Education.

Ping, C. (2005). Motivating Students to Learn. British Journal of Educational Technology, 50(1), 12-63.

Purvis, A., Dave, C. \& Abbi, F. (2009). Beyond Peer Observation of Teaching. SEDA paper, 23-28.

Putnam, J. (1985). Perceived Benefits and Limitations of Teacher Educator Demonstration Lessons. Journal of Teacher Education, 36(6), 36-41.

Richards, J. C. \& Charles, L. (1991). Teacher Development through Peer Observation. Tesol Journal, 1(2), 7-10.

Rinehart, G. (1993). Quality Education: Applying the Philosophy of Dr. W. Edwards Deming to Transform the Educational System. ASQ Quality Press.

Rosenthal, R., Ralph, L. R. \& Alan, E. K. (2009). Artifacts in Behavioral Research: Robert Rosenthal and Ralph L. Rosnow's Classic Books. Oxford University Press, USA.

Sachs, J. \& Mitch, P. (2014). Peer Review of Learning and Teaching in Higher Education: International Perspectives. Peer Review of Learning and Teaching in Higher Education: International Perspectives, 1-219.

Santos, L. M. D. (2016). Foreign Language Teachers' Professional Development through Peer Observation Programme. English Language Teaching, 9(10), 39-42.

Shortland, S. (2004). Peer Observation: A Tool for Staff Development or Compliance?. Journal of Further and Higher Education, 28(2), 219-228.

Shortland, S. (2010). Feedback within Peer Observation: Continuing Professional Development and Unexpected Consequences. Innovations in Education and Teaching International, 47(3), 295-304.

Stodolsky, S. (1984). Teacher Evaluation: The Limits of Looking. Educational Researcher, 13(9), 11-18. https://doi.org/10.1080/0309877042000206778

Thampy, H., Michael, B., \& Prasheena, N. (2015). Peer-Supported Review of Teaching: An Evaluation. Education for Primary Care, 26(5), 306-310.

Thampy, H. \& Nicole, K (2015). Peer Observation of Clinical Teaching: A Guide. MedEdPublish.

Wickstrom, G. \& Bendix, T. (2000). The "Hawthorne Effect" - What Did the Original Hawthorne Studies Actually Show?. Scandinavian Journal of Work, Environment and Health, 26(4), 363-367. https://doi.org/10.5271/sjweh.555

Yon, M., Charles, B. \& Gary, K. (2002). Evidence of Effective Teaching: Perceptions of Peer Reviewers. College Teaching, 50(3),104-110. 